\title{
Effective cost allocation method in an industrial enterprise environment in mining industry
}

\author{
Kamila Janovská ${ }^{*}$, Śárka Vilamová ${ }^{1}$, Marian Piecha $^{2}$, Josef Kutáć $^{1}$, Roman $_{\text {Kozel }}{ }^{3}$, and \\ Jana Čitbajová ${ }^{4}$ \\ ${ }^{1}$ VSB-Technical University of Ostrava, Faculty of Materials Science and Technology, 17. listopadu \\ 2172/15, 70800 Ostrava - Poruba, Czech Republic \\ ${ }^{2}$ Ministry of Industry and Trade Czech Republic, Na Františku 32, 11015 Praha 1, Czech Republic \\ ${ }^{3}$ VSB-Technical University of Ostrava, Faculty of Mining and Geology, 17. listopadu 2172/15, 708 \\ 00 Ostrava - Poruba, Czech Republic \\ ${ }^{4}$ Technical University of Košice, Faculty of Mining, Ecology, Process Control and Geotechnologies, \\ Institute of Earth Resources, Park Komenského 19, 04200 Košice, Slovakia
}

\begin{abstract}
The ability to optimize costs based on knowledge of business processes during the period of change represented by the fourth industrial revolution is absolutely crucial. This paper is dedicated to the issue of cost management and allocation of overhead costs using the Activity Based Costing (ABC) method under the condition of an industrial enterprise. The aim of the authors was to propose a model that focuses on the allocation of overhead costs and calculation of assignment rates of overhead activities, which mutually cooperate. The proposed model enables objective stipulation of assignment rates of mutually cooperating overhead activities using exact economic-mathematical methods - the Leontief structural model. It was proven that use of the structural model, even in the case of multiple overhead and primary activities, leads to the considerable simplification of calculations when determining the assignment rates of overhead activities.
\end{abstract}

\section{Introduction}

In order to maintain the competitiveness of industrial enterprises, especially small and medium-sized enterprises, in the period of change represented by the fourth industrial revolution, the ability to optimise costs conditioned by a knowledge of corporate processes is a crucial skill at present. Without a detailed knowledge of costs, both those for individual processes and those for the final products of the industrial enterprise as a whole, industrial enterprises will be unable to define and adopt the right decisions to ensure sufficient profit and cash flow for the functioning and growth of the enterprise.

Current changes in the business environment can be summarised into the following points:

1. Significant growth of the structure of executed outputs,

2. Rising demands on the quality of provided outputs,

\footnotetext{
* Corresponding author: kamila.janovska@,vsb.cz
} 
3. Need to supply a wide range of outputs at shorter time intervals,

4. Shortening of the lifetime of offered products.

The outcome of these factors leads to changes in the cost structure, particularly by reducing the share of primary (variable) costs in relation to overhead (fixed) costs, which is given mainly by the increasing degree of manufacturing automation. The share of overhead costs needed to ensure support, servicing, information and controlling activities is rising. These conclusions logically result in the need for the better orientation of management measures not only with respect to the costs for final outputs, but also to the overhead costs for assurance processes [1]. Management measures do not refer merely to the need for managing the effectiveness of continuously rising overhead costs.

It is equally essential to address the issue of appraising the allocation of overhead (servicing) activities (e.g. transport, logistics, maintenance, sales), which are objects of overhead costs, to the primary activity (production). Subsequently, it is necessary to address the issue of distributing overhead costs in the primary (production) activities among outputs (products, activities) which are the final objects of overhead costs (see Fig. 1.).

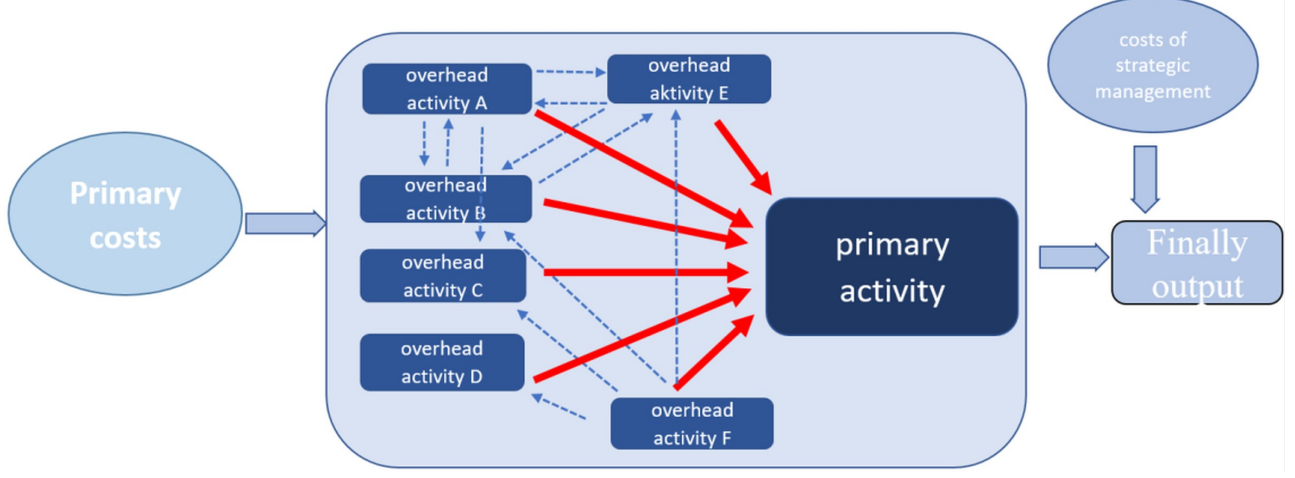

Fig. 1. Allocation of overhead costs of overhead activities to primary activities [actual processing]

The submitted article is dedicated to the issue of cost management and allocation of overhead costs using the Activity Based Costing (ABC) method under the condition of an industrial enterprise. Extensive literary research was conducted, which proved that the process of implementing the $\mathrm{ABC}$ method at domestic industrial enterprises is not very widespread and that the allocation of overhead costs for overhead activities to primary activities is particularly problematic.

\section{Current state of scientific discovery of the examined issue - literary research}

Most enterprises perceive the fact that in the period of change brought about by the fourth industrial revolution, traditional cost management methods will no longer suffice; it is necessary to start using management methods that can keep up with the dynamically evolving economic environment [2]. Hence, a process-based view of the enterprise, based on reviewing corporate processes and activities which create value for customers and generate costs, is being increasingly applied at industrial enterprises. This view of the corporate transformation process is employed in increasingly more new management instruments and methods, which include Activity-Based Costing. The principle of the ABC method differs from the traditional approach of calculation methods, because it divides consumed resources into activities with the aim of achieving the distribution of overhead 
costs based on the actual cause of their accrual. The ABC calculation returns to the cause and effect relation, because it strives not to divide resources into centres, but into activities, with the aim of distributing overhead costs according to the actual cause of their accrual.

As for application of the ABC method, it may be claimed that the level of acceptance into corporate practice is unfortunately low at domestic industrial enterprises.

The ABC method was created in the USA and its founders are deemed to be the American authors Cooper and Kaplan [3], who discuss it in the article "Measure Costs Right: Make the Right Decisions" of 1988. Corporate practice attempted to use the ABC method many years earlier; for instance Bouquin [4] mentions a certain degree of application of the $\mathrm{ABC}$ method in corporate management as far back as in the 1860 s by the American company General Electric, which stood at the birth of many other commonly used management methods and approaches (e.g. the GE matrix, etc.). Since tine 1990s, the $\mathrm{ABC}$ method has been implemented and used by companies such as Coca-Cola, Apple Computer, IBM, HP, AT\&T, P\&G, Siemens and many others [5].

The processing industry with heterogeneous production and assembly technologies currently have the most experience in applying the ABC method. However, the method is fairly widely applied also in non-production sectors - e.g. in commercial companies, banking, insurance and transport [6]. Many authors (e.g. [7, 8]) agree that application of the $\mathrm{ABC}$ method is more beneficial at medium-sized and large enterprises. The reason is the high variability of products and services, the greater quantity of products and services, the wider range of customers, higher degree of automation of corporate processes and more extensive management structure of the enterprise, resulting in a relatively high share of overhead costs in total costs. As stated by one of many studies [9] concerning the degree of acceptance of the $\mathrm{ABC}$ method among enterprises, the lower degree of use among small enterprises may be caused by the relative high initial costs for implementation. Some studies state a degree of implementation exceeding 50\% in the USA [10].

The oldest and most often cited studies concerning the ABC method include the study by Innes and Mitchel of 1991, which was conducted among the largest British enterprises at the time. The study was repeated twice with the same questionnaire, first in 1994 and then again in 1999. The study of 1999 offered interesting findings compared to the first survey in 1994. Between the follow-up studies, the number of enterprises using the ABC method did not increase, but the number of enterprises that refused to implement it did. Whereas in 1994 its distribution among production enterprises and service enterprises was comparable, in 1999 the $\mathrm{ABC}$ method was far more common in the financial sector (40\% of enterprises) than in the production sector (14\% of enterprises). A stronger inclination towards the ABC method in Great Britain was not confirmed even in another survey in 2007, the result of which include the finding of only $15 \%$ of distribution of the method amount major British enterprises in the reviewed sample. Another English-speaking country, where interesting research on the level of distribution of the $\mathrm{ABC}$ method was conducted, was Australia. Here, the identified distribution of the method was incomparably higher than in Great Britain. The survey conducted in Australia in 1998 indicated a degree of acceptance of the ABC method of 52\%, while the subsequent survey in 2004), which focussed on mediumsized and large Australian enterprises, reported a $78 \%$ distribution of this method. The conducted scientific investigations indicate that the distribution of the $\mathrm{ABC}$ method in nonEnglish-speaking European countries is lower. For instance, in his article "Activity-Based costing: how far have we come internationally?", it states that the lower distribution of the method in continental Europe is due to the use of different cost systems with a longer tradition and higher degree of elaboration than was the case in the United States before the introduction of the $\mathrm{ABC}$ method.

Only very few surveys of the use of the ABC method in corporate practice in the Czech Republic have been conducted. An overview of the status of practical application of this 
method in the Czech Republic is offered primarily by the survey conducted in 2004, which states that of a sample of 140 Czech industrial enterprises, $51 \%$ of enterprises have never examined the $\mathrm{ABC}$ system, a full $18 \%$ of enterprises have looked at the $\mathrm{ABC}$ system but then rejected its application, $23 \%$ of enterprises realistically considered the application of the method, $3 \%$ of enterprises where in the implementation phase and only $5 \%$ of enterprises were actively using it. Awareness of the method increases with the size of the enterprise, and consultancy agency often help with its implementation. A survey conducted in 2007 determined that there was a slight growth in use of the $\mathrm{ABC}$ calculation within this method, specifically this referred to use at $8 \%$ of Czech enterprises in the contacted selection sample.

The related issue of allocating overhead costs is addressed in his thesis by Novák - he maps the issue of overhead cost allocation and the use of modern cost management and calculation methods in the conditions of domestic manufacturing enterprises, the analysis of overhead cost structure and development and the creation of a simple guide on how to effectively approach the overhead cost management and allocation based on key rules and principles, while using various cost instruments. Of the total 8,070 enterprises address (enterprises in various sectors, based in the Czech Republic with more than 20 employees), 291 responded. Among other, they examined the distribution of the ABC method as an instrument for managing and measuring performance. Of the responds who replied, $22 \%$ used the method. ABC is among the above-average used management instruments in the paper and chemical production industry, and of the tertiary sector in the branches of transport and connections and activities concerning real estate and lease. On the contrary, low interest is apparent in the sectors of electrical instruments and construction. It may be assumed that of the companies that replied, there is a greater share of those interest in new management methods than in the total sample. For this reason, the distribution of $\mathrm{ABC}$ among Czech enterprises is probably lower than suggested.

\section{Application of the ABC calculation method - allocation of costs for overhead activities to primary activities - proposed model}

The fundamental step in application of the $\mathrm{ABC}$ calculation model is an activity analysis, consisting of several partial, consecutive steps which aim to calculate the individual costs for primary activities. Within the activity analysis, the specific partial steps are as follows:

1. Stipulate the activity benchmarks.

2. Stipulate the degree of activity output.

3. Calculate the individual (variable) activity costs.

4. Allocate the costs of support activity to primary activities.

The problematic part of allocating the costs of overhead activities to primary activities in corporate practice is the fact that overhead activity output is not consumed only by the primary activities, but also mutually by the other overhead activities. The problem then becomes the objective stipulation of allocation rates of outputs of mutually cooperating overhead activities, because their allocation links create mutual cycles.

Based on a discussion with experts from industrial enterprises, it may be stated that if they do address this issue, they do so in gradual steps (iterations), until the predefined accuracy is achieved, meaning a minimal difference in allocation rates in consecutive steps. The aim of all these steps is to calculate such cost rates (prices) for overhead activity output allocated to primary activities, which will ensure that the value of the product of these calculated rates and the quantity of overhead activity outputs (in the form of benchmarks) 
allocated to primary activities is equal to the sum of the values of primary costs of all overhead activities. This ensures that even if the overhead activities variously mutually transfer their outputs, in the end all of their primary costs will be allocated to the primary activity in the form of secondary costs, and these will then be distribute with the help of other activities in the form of benchmarks to the calculated outputs (products) of primary activities.

If we take into account that, in practice, there tends to be a high number of overhead activities, then the iteration calculation is usually very lengthy and ineffective, because if any changes occur in the course of calculation, e.g. in primary costs, the quantity or allocated outputs in the form of overhead activity benchmarks, all of the calculations must be conducted again and repeatedly. The number of overhead activities in the real conditions of industrial enterprises also determines the number of iterations leading to the calculation of final rates of the assigned outputs. In practice, this means that such iterations number in the tens. Such calculation is complicated, lengthy and every further intervention in the defined task is difficult (change of plan, calculation of variant solutions, divergence from the planned course).

Proposed model for allocation of overhead activity costs.

The proposed model focusses on the allocation of overhead costs and calculation of assignment rates of overhead activities, which mutually cooperate. The model enables the objective stipulation of assignment rates of mutually cooperating overhead activities using exact economic-mathematical methods - the Leontief structural model.

Calculation structure:

I. Composition of a chessboard table of the structural model - natural expression.

Based on the input data (management accounting and operative production records), a chessboard table of the structural model in natural expression is composed, which describes the conditions for the existence of a balance between resources and needs in a production consumption system (industrial enterprise).

II. Composition of a chessboard table of the structural model - natural expression.

The benchmarks of the individual overhead activities need not be substantive identical (e.g. hours, $\mathrm{t}, \mathrm{CZK}$, unit...), which is why the chessboard table in natural expression must be modified into value expression.

III. Composition of Matrix A - matrix of direct consumption coefficients.

Matrix $\mathbf{A}$ is a matrix of technological coefficients, which expresses which products were directly consumed to produce the required output (final consumption vector) in the production - consumption system.

Calculation of Matrix A - matrix of direct consumption coefficients

where:

$$
x_{i j}=a_{i j} x_{j} \quad i, j=1,2, \ldots, n
$$

aij the coefficient of direct specific production consumption of sector $\mathrm{i}$ in sector $\mathrm{j}$ (quantity of production of sector i needed to produce a production unit in sector $\mathrm{j})(\mathrm{i}, \mathrm{j}=1,2, \ldots, \mathrm{n})$;

$x i \quad$ total value of production of sector $\mathrm{i}(\mathrm{i}=1,2, \ldots, \mathrm{n})$

xij total consumption of production of sector $\mathrm{i}$ in sector $\mathrm{j}$ of the given production - consumption system $(i, j=1,2, \ldots, n)$

IV. Calculation of Matrix B - matrix of complex consumption coefficients

Matrix B is the matrix of complex consumption coefficients, which expresses the total quantity of production in sector $\mathrm{i}$ needed to produce a production unit in sector $\mathrm{j}$ designated for final consumption - sale. Indirect consumption is mediate consumption, given by the fact that the respective sector $\mathrm{j}$ needs, in addition to the respective sector $\mathrm{i}$, the production 
of other system sectors, which also consume production from the respective sector i. Matrix $B$ is an inversion matrix of matrix $(\mathrm{E}-\mathrm{A})^{-1}$.

Calculation of Matrix B - matrix of complex consumption coefficients

$$
\mathrm{B}=(\mathrm{E}-\mathrm{A})^{-1}
$$

where:

$E \quad$ matrix unit of the order n

$B$ matrix of complex (direct and indirect) consumption coefficients of the production fo sector $i$ in sector $j$ bij; bij $\geq a i j$; aij $\geq 0$

$\mathrm{V}$. Calculation of the final value of assignment rates of outputs of mutually cooperating overhead activities.

\section{Application of the proposed model at a specific industrial enterprise - discussion of achieved results}

The structural analysis method was used in the application of exact decision-making methods when solving the issue of effective calculation of assignment cost rates for overhead activity performance. The text below simulates the calculation within 5 overhead activities based on their primary costs and the quantity of created and assigned output in the form of benchmarks. In the presented case, the overhead activities transfer their outputs among them in hours appraised at the respective cost rate. Table 1. contains the simplified input data for the calculation of assignment cost rates for outputs mutually assigned between overhead activities within the selected enterprise.

Table 1. Input data for calculating the assignment cost rates of outputs mutually transferred between overhead activities in the form of benchmarks using the $\mathrm{ABC}$ method at a selected metallurgical enterprise [own processing].

\begin{tabular}{|c|c|c|c|c|c|c|c|c|c|c|}
\hline \multicolumn{11}{|c|}{$\begin{array}{l}\text { Input data for the calculation of assignment cost rates for outputs mutually assigned } \\
\text { between overhead activities within the selected enterprise in the form of benchmarks }\end{array}$} \\
\hline \multicolumn{6}{|c|}{ Assigning activities } & \multicolumn{5}{|c|}{ Receiving activities } \\
\hline 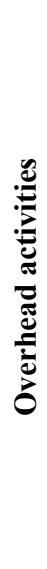 & 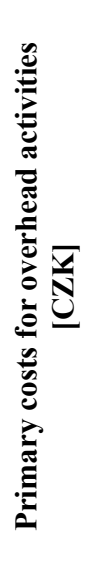 & 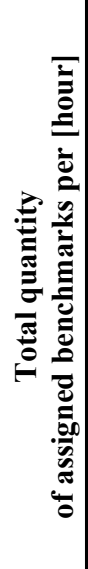 & 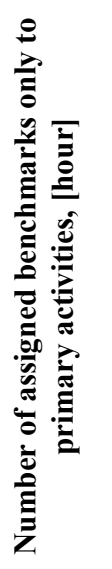 & 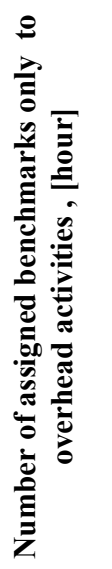 & 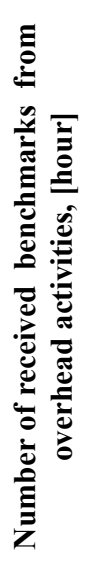 & 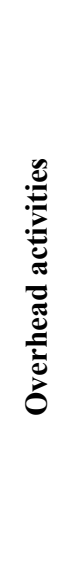 & 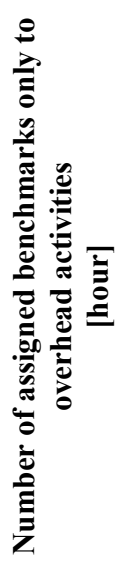 & 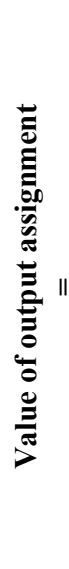 & 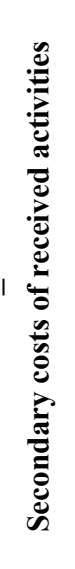 & $\underset{\mathcal{U}}{\tilde{U}}$ \\
\hline \multirow[t]{2}{*}{$\mathbf{A}$} & 999 & 9 & \multirow[t]{2}{*}{4500} & \multirow[t]{2}{*}{5000} & \multirow[t]{2}{*}{9000} & $\bar{B}$ & 2000 & \multicolumn{3}{|c|}{210520} \\
\hline & 970 & 500 & & & & $\mathrm{C}$ & 3000 & \multicolumn{3}{|c|}{315780} \\
\hline B & 2000 & 23 & 13000 & 10000 & 5000 & $\bar{A}$ & 3000 & \multicolumn{3}{|c|}{260880} \\
\hline
\end{tabular}




\begin{tabular}{|c|c|c|c|c|c|c|c|c|}
\hline & 080 & 000 & & & & $\mathrm{C}$ & 5000 & 434800 \\
\cline { 6 - 9 } & & & & & & $\mathrm{D}$ & 2000 & 173920 \\
\hline $\mathbf{C}$ & 3000 & 30 & 15000 & 15000 & 27 & $\mathrm{D}$ & 9000 & 900000 \\
\cline { 6 - 9 } & 000 & 000 & & & 000 & $\mathrm{E}$ & 6000 & 600000 \\
\hline $\mathbf{D}$ & 3999 & 39 & 19000 & 20000 & 11 & $\mathrm{~B}$ & 3000 & 307680 \\
\cline { 6 - 8 } & 840 & 000 & & & 000 & $\mathrm{E}$ & 17000 & 1743520 \\
\hline $\mathbf{E}$ & 4999 & 47 & 22000 & 25000 & 23 & $\mathrm{C}$ & 19000 & 2021220 \\
\cline { 6 - 8 } & 860 & 000 & & & 000 & $\mathrm{~A}$ & 6000 & 638280 \\
\hline
\end{tabular}

Based on the input data, a chessboard table of the structural model was compiled (see Table 2., 3.).

Table 2. Chessboard table of the structural model [own processing].

\begin{tabular}{|c|c|c|c|c|c|c|c|}
\hline \multirow[b]{2}{*}{ Activity } & \multicolumn{5}{|c|}{$\begin{array}{c}\text { Value of assigned outputs in the form } \\
\text { of benchmarks (BM) for overhead } \\
\text { activities [hour] }\end{array}$} & \multirow{2}{*}{$\begin{array}{c}\begin{array}{c}\text { Assigned } \\
\text { outputs } \\
\text { (BM) to } \\
\text { primary } \\
\text { activity } \\
\text { [hour] }\end{array} \\
\mathrm{H}\end{array}$} & \multirow{2}{*}{$\begin{array}{c}\text { Assigned } \\
\text { outputs } \\
\text { (BM) } \\
\text { total } \\
\text { [hour] }\end{array}$} \\
\hline & A & B & $\mathrm{C}$ & $\mathrm{D}$ & E & & \\
\hline $\mathbf{A}$ & & 2000 & 3000 & & & 4500 & 9500 \\
\hline B & 3000 & & 5000 & 2000 & & 13000 & 23000 \\
\hline C & & & & 9000 & 6000 & 15000 & 30000 \\
\hline D & & 3000 & & & 17000 & 19000 & 39000 \\
\hline $\mathbf{E}$ & 6000 & & 19000 & & & 22000 & 47000 \\
\hline
\end{tabular}

Table 3. Chessboard table of the structural model [own processing].

\begin{tabular}{|c|c|c|c|c|c|c|c|}
\hline \multirow[b]{2}{*}{ 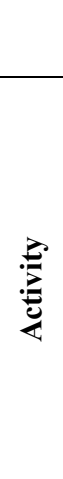 } & \multicolumn{5}{|c|}{ Value of assigned outputs, [CZK] } & \multirow[b]{2}{*}{ 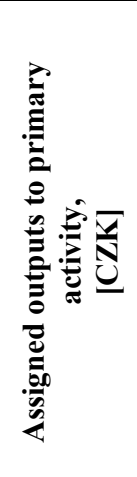 } & \multirow[b]{2}{*}{ 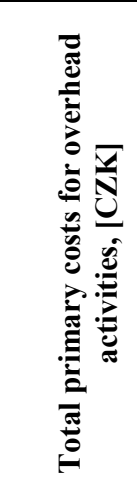 } \\
\hline & $\mathrm{A}$ & B & $\mathrm{C}$ & $\mathrm{D}$ & $\bar{E}$ & & \\
\hline $\mathbf{A}$ & & 210520 & 315780 & & & 473670 & 999970 \\
\hline $\mathbf{B}$ & 260880 & & 434800 & 173920 & & $\begin{array}{c}1130 \\
480\end{array}$ & 2000080 \\
\hline $\mathbf{C}$ & & & & 900000 & 600000 & $\begin{array}{c}1500 \\
000\end{array}$ & 3000000 \\
\hline $\mathbf{D}$ & & 307680 & & & 1743520 & $\begin{array}{c}1948 \\
640\end{array}$ & 3999840 \\
\hline $\mathbf{E}$ & 638280 & & $\begin{array}{c}2021 \\
220 \\
\end{array}$ & & & & 4999860 \\
\hline
\end{tabular}


The data from Table 3. was used to compile matrix A - matrix of direct consumption coefficients and subsequently to calculate matrix B - matrix of complex consumption coefficients (Table 4 and 5).

Table 4. Matrix A - matrix of direct consumption coefficients.

\begin{tabular}{|c|c|c|c|c|c|}
\hline & $\mathbf{A}$ & $\mathbf{B}$ & $\mathbf{C}$ & $\mathbf{D}$ & $\mathbf{E}$ \\
\hline $\mathbf{A}$ & 0 & 0.105 & 0.105 & 0 & 0 \\
\hline B & 0.261 & 0 & 0.145 & 0.043 & 0 \\
\hline C & 0 & 0 & 0 & 0.225 & 0.26 \\
\hline $\mathbf{D}$ & 0 & 0.154 & 0 & 0 & 0.349 \\
\hline E & 0.638 & 0 & 0.674 & 0 & 0 \\
\hline
\end{tabular}

Table 5. Matrix B - matrix of complex consumption coefficients, which respect and include the volume of mutual assignments between overhead activities

\begin{tabular}{|c|c|c|c|c|c|}
\hline & A & B & C & D & E \\
\hline A & 1.050 & 0.116 & 0.148 & 0.038 & 0.031 \\
\hline B & 0.312 & 1.048 & 0.225 & 0.096 & 0.060 \\
\hline C & 0.166 & 0.059 & 1.185 & 0.269 & 0.236 \\
\hline D & 0.321 & 0.201 & 0.346 & 1.087 & 0.421 \\
\hline E & 0.782 & 0.114 & 0.893 & 0.206 & 1.179 \\
\hline & $\mathbf{2 . 6 3 1}$ & $\mathbf{1 . 5 3 7}$ & $\mathbf{2 . 7 9 8}$ & $\mathbf{1 . 6 9 6}$ & $\mathbf{1 . 9 2 8}$ \\
\hline
\end{tabular}

Calculated figures of the final value of assignment cost rates for overhead activities per benchmark unit for all the activities (overhead and primary) using the structural analysis method:
A: $2.631 * 105.26=276,994 \mathrm{CZK} /$ benchmark unit
B: $1.537 * 86.96=133,742 \mathrm{CZK} /$ benchmark unit
C: $2.798 * 100.00=279,849 \mathrm{CZK} /$ benchmark unit
D: $1.696 * 102.56=173,999 \mathrm{CZK} /$ benchmark unit
E: $1.928 * 106.38=205,041 \mathrm{CZK} /$ benchmark unit

When using the iteration distribution of overhead activity costs to primary activities based on benchmarks - the ABC (Activity Based Costing) method on a chosen industrial enterprise, 193 calculation steps were needed using the iteration method to determine a result with zero divergence (the number of steps depends on the predefined degree of divergence). The achieved results indicate that the value of assignment rates to the benchmark unit calculated using the structural analysis method and repeated reading method are identical.

The proposed procedure uses the characteristics of complex consumption coefficients of the structural model, resulting from the inversion of the direct consumption coefficient matrix. These complex coefficients already include all the rates (assignments) between the matrix elements and thus allow, in our case, the stipulation of the size of assignment rates of mutually cooperating activities in a single step. The calculation if fast, accurate and enables change implementation and the processing of variant solutions in real time. It was proven that use of the structural model, even in the case of multiple overhead and primary activities, leads to the considerable simplification of calculations when determining the 
assignment rates of overhead activities. The final results are achieved in a single step, by inversion of the direct consumption coefficient matrix. The result is accurate, unlimited by a predefined difference between the rates of the last two steps.

The model is very clear and enables flexible reaction to changes in the input values, enables the fast calculation of variant solutions and evaluation of the impact intensity of changes in the input factors on the resulting assignment price of activities, and thereby on the cost level of individual calculated products.

\section{Conclusions}

The trend of progressive worldwide globalisation means that industrial enterprises are under rising competitive pressure and must build up their competitive edge by innovating transformation processes, developing human capital by high qualification which is characteristics for industrial companies or investing into new technologies. It is entirely obvious that enterprises should react to this situation also with the thorough management of their costs. Management decision-making may be assisted by SW products designed for specific purposes. Most industrial enterprises perceive this need and understand that in the period of change brought about by the fourth industrial revolution, traditional cost management methods will no longer suffice; it is necessary to start using management methods that can keep up with the dynamically evolving economic environment.

Calculation as one of the basic instruments of management accounting depicts both basic poles of the entrepreneurial process - naturally expressed output and its value characteristic. For this reason, it is a crucial tool which allows managers to identify the relations and behaviour of costs depending on the volume and structure of outputs, and stipulate the costs of corporate outputs as such. At present, there is a whole range of expert theses engaged in assessing the cost of enterprise outputs. The issue of calculating activity cost units with a focus on mutual consumption and self-consumption of the outputs of auxiliary activities is addressed by the thesis. Theses address the issue of effective cost management and optimisation of process and activity costs in metallurgical enterprises. Current competitive pressure obliges iron producers to increasingly include the costs for production and logistics processes as an important criterion in the decision-making process when comparing available raw materials and evaluating the efficiency of their use. The results of a case study concerning cost management at foundries in the Czech Republic are presented in the thesis.

A process-based view of the enterprise, based on reviewing corporate processes and activities which create value for customers and generate costs, is being increasingly applied at industrial enterprises. This process-based view of the corporate transformation process is employed in increasingly more new management instruments and methods, which include Activity-Based Costing. This method is primarily designated for industrial enterprises as an instrument for stipulating the assignment rates of mutually cooperating overhead activities, and is particularly suitable for small and middle-sized enterprises with diverse technological procedures, which do not have SW products from companies engaged in the consultancy or production and implementation of SW products.

The proposed method enables the stipulation of assignment rates for mutually cooperating activities using exact economic-mathematic methods - the Leontief structural model, even in cases when the individual activities cooperate and transfer their output (activity) between each other. The proposed procedure uses the characteristics of complex consumption coefficients of the structural model, resulting from the inversion of the direct consumption coefficient matrix. These complex coefficients already include all the rates (assignments) between the matrix elements and thus allow the stipulation of the size of assignment rates of mutually cooperating activities in a single step. 
By applying this method, the lowest possible level of assignment costs for overhead activities to primary activities is calculated, thus ensuring the allocation of overhead activity costs to primary activities at a value that is equal to the value of the primary costs of these overhead activities.

The proposed model:

- Fully respects the mutual relations of assignments between activities.

- The final results - assignment cost rates of overhead activities to primary activities are stipulated in a single step.

- Use of the structural model leads to the substantial simplification of calculations even in the case of multiple activities.

- The calculation enables change implementation and the processing of variant solutions in real time.

Costs and cost calculations hold a significant position in the data base of cost controlling. Controlling obtains the information needed to perform all of its functions by applying various methods. Exact methods of decision-making based on logical mathematical models may become an important source of quality information, as yet undervalued by corporate (controlling) practice. Yet, the mathematical apparatus and software support for their application in industrial corporate practice are sufficiently ready.

\section{Acknowledgement}

The work was supported by the specific university research of Ministry of Education, Youth and Sports of the Czech Republic No. SP2019/62.

\section{References}

1. M. Landa, Účetnictví podniku: informační zdroj podnikatelských rozhodnutí (Eurolex, Bohemia, 2006)

2. R. Kozel, Š. Vilamová, P. Baránek, V. Friedrich, Z. Hajduová, and M. Behún, Acta Montanistica Slovaca, 22;4, 439-447 (2017)

3. R. Cooper, R.S. Kaplan, The CPA Journal, 60:2, 38-48 (1990)

4. H. Bouquin, Comptabilité de Gestion (Economica, Paris, 2006)

5. J. Basl, P. Majer, M. Šmíra, Teorie omezeni v podnikové praxi: Zvyšování výkonnosti podniku nástroji TOC (Grada Publishing, Prague, 2003)

6. B. Král, Manažerské účetnictví (Management Press, Prague, 2006)

7. D. Cagwin, M. Bouwman, Management Accounting Research, 13:1, 1-40 (2002)

8. K. Krumwiede, Management Accounting, 79:10, 32-36 (1998)

9. S. Jänkälä, H. Silvola, Journal of Small Business Management, 50:3, 498-523 (2012) DOI: 10.1111/j.1540-627X.2012.00364.X

10. J. Majerová, The international spread of Activity-based Costing (Oeconomica Publishing House, Praha, 2010) 